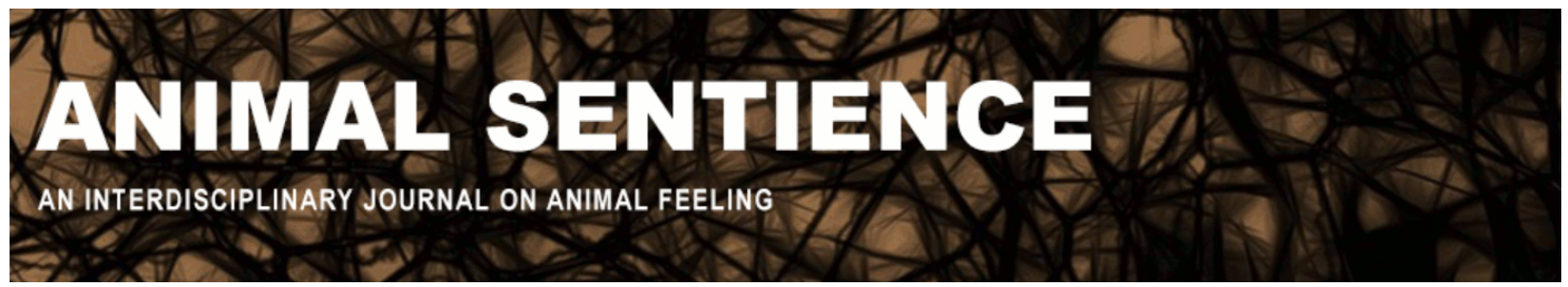

Browning, Heather (2017) Anecdotes can be evidence too. Animal Sentience 16(13)

DOI: $10.51291 / 2377-7478.1246$

Date of submission: 2017-11-07

Date of acceptance: 2017-11-09

(c)

This article has appeared in the journal Animal

Sentience, a peer-reviewed journal on animal

cognition and feeling. It has been made open access,

free for all, by WellBeing International and deposited

in the WBI Studies Repository. For more information,

please contact

wbisr-info@wellbeingintl.org.

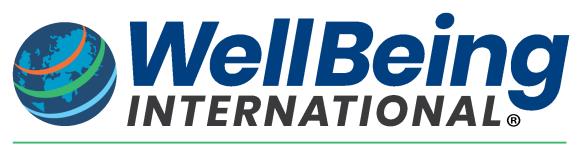

SOLUTIONS FOR PEOPLE, ANIMALS AND ENVIRONMENT 


\title{
Anecdotes can be evidence too
}

Commentary on Birch on Precautionary Principle

\author{
Heather Browning \\ School of Philosophy \\ Australian National University
}

\begin{abstract}
Birch's criterion for the precautionary principle imposes a high evidential standard that many cases will fail to meet. Reliable, relevant anecdotal evidence suggestive of animal sentience should also to fall within the scope of the precautionary principle. This would minimize potential suffering (as happened in the case cephalopods) while further evidence is gathered.
\end{abstract}

Heather Browning is a zookeeper and PhD candidate in the School of Philosophy at the Australian National University, working on conceptual and methodological issues in the measurement of subjective animal welfare. philrsss.anu.edu.au/profile/heather-browning

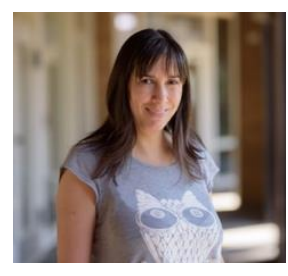

1. Scope of the precautionary principle. Birch (2017) provides a formulation of the precautionary principle as a scientific criterion to make it more applicable to animal sentience and the use of animals. He divides the principle into an epistemological component (what standards should we use to judge whether we have sufficient evidence to consider an animal most likely sentient?), which he calls BAR and a practical component (what action should we take on the basis of this evidence?), which he calls ACT. The concern with Birch's specification of BAR is that it may set an unreasonably high evidential requirement that would then rule out many of the cases in which we wish to apply the precautionary principle.

The precautionary principle was originally intended to apply to decision-making under conditions of uncertainty where there is a possibility of doing great harm. According to the original document of the Commission of European Communities, it should be applied "where scientific information is insufficient, inconclusive or uncertain and where there are indications that the potential effects ... may be potentially dangerous" (cited in Croney \& Millman 2007, p. 559). Birch outlines the general animal sentience precautionary principle (ASPP): "where there are threats of serious, negative animal welfare outcomes, lack of full scientific certainty as to the sentience of the animals in question shall not be used as a reason for postponing cost-effective measures to prevent those outcomes" (3). However, the cases in which we have less than full scientific certainty vary widely, from a level of confidence less than 1 all the way down to having no idea either way (Steel 2015).

Many of these cases will not fall under the conditions described in BAR: "for the purposes of formulating animal protection legislation, there is sufficient evidence that animals of a particular order are sentient if there is statistically significant evidence, obtained by experiments that meet normal scientific standards, of the presence of at least one credible indicator of sentience in at least one species of that order" (5). Although this is intended to be a lower than normal bar 
for evidence, as only a single credible indicator is required, the call for statistically significant results obtained through the process of scientific experimentation is still quite rigorous. If we accept the strong formulation of BAR, there may no longer be the uncertainty that the precautionary principle is designed to address, leaving instead just the standard scientific inference-to-the-best-hypothesis to account for the available evidence. This could be too demanding for the sentience hypothesis in many cases, thereby ruling out or deferring the protection of sentient species and causing the potential harm the principle was intended to minimize. If the precautionary principle is intended to provide "tools and guidelines for decisions in which the science is inadequate" (deFur \& Kaszuba 2002, p. 165), then BAR will fail to rule on many such cases. So, which cases should we allow?

Birch rules out applying the precautionary principle in all cases where there is no evidence - a "default presumption of sentience" (5) that could create significant practical roadblocks to animal use, possibly without warrant, and would undermine the role of scientific work in helping determine the scope of animal protection legislation. However, there is another set of cases between those in which we have no evidence either way and those in which we have strong scientific evidence of at least one indicator of sentience. These are the cases in which we have some indications of sentience through less rigorous observational or anecdotal evidence. This fits with Birch's comment that while "we should require some evidence ... the bar should be set at a level low enough to avoid a prolonged period of inaction that may turn out, retrospectively, to have allowed a serious and preventable harm to occur" (3). I suggest that reliable anecdotal evidence may be sufficient to prompt us to apply the precautionary principle in these cases, as this is an indicator of the potential for significant harm and seems to be precisely the sort of case for which this principle is intended.

2. Anecdotal evidence. Anecdotal evidence has frequently been criticised as unscientific, too subjective, and prone to bias and anthropomorphism, leading to misinterpretation of the observations (Bekoff 2000, Heyes 1998, Moore \& Stilgoe 2009). However, the use of carefully selected observations and anecdotes can overcome some of these issues. Bates \& Byrne (2007) argue that carefully collected anecdotes can form a valuable source of information - "the plural of anecdote can be data" (14). Rollin (1997) argues that the use of anecdotal evidence is appropriate so long as there is a plausible link from the story to the inference made, supported by common sense and background knowledge. Use of any story from someone who has encountered a member of the species of interest is clearly insufficient, but repeated independent observations by researchers and husbandry professionals deeply familiar with the species should not be dismissed so lightly.

This is the case for much work in animal cognition and behavioural ecology where rare observations of particular behaviour patterns may be all the evidence available. Russon \& Galdikas (1993) used the analysis of a large collection of single observations of spontaneous behaviour in order to establish the capacity for imitation in orangutans - something that had frequently been observed but never scientifically accepted because of the 'anecdotal' nature of the reports and the inability to replicate results in a lab setting. Bates \& Byrne (2007) describe the case of studies of infanticide: when researchers started looking into the cases described, they found that hunters and explorers had been witnessing the events for a century, "but each single observation had been rejected as anecdotal and unsubstantiated" (13). Wider sampling 
and observation confirmed these early observations: "If these anecdotes had been ignored, we would still be blind to the causes and consequences of this highly significant behaviour" (14). In cases like these, the right sort of anecdotal evidence may be the best source of evidence we have available: "if no formal evidence can be found, then anecdotal information provides the best and only information on which to base our understanding and decisions" (Enkin \& Jadad 1998, p. 965).

Anecdotal evidence is often cited as a good source of information to derive testable hypotheses and guide the direction of future study (Bekoff 2000, Burghardt 1985, Kamil 1988). This is useful precisely because well-collected anecdotal evidence often points at features that will later be confirmed through more rigorous scientific analysis. Where this is likely to be the case, we have a reason to apply the precautionary principle on the basis of reliable anecdotal evidence.

3. Lesson from the case of cephalopods. An example in which the precautionary principle could have been usefully applied in the face of long-running anecdotal evidence is the cephalopods (octopuses, squid and cuttlefish). Popular accounts and observations have long noted the cognitive abilities of octopuses (see anecdotal evidence described by Moynihan 1997, and stories collected by Linden 2002); however, underperformance in experimental settings led to these stories being ignored by researchers in favour of reductionist explanations that did not require intelligence or sentience. Godfrey-Smith (2016) suggests that the reason the experimental work failed to capture cephalopod abilities may have been the unpredictable nature of octopuses, who do not settle quietly into laboratory settings and often "turn the apparatus around them to their own octopodean purposes" (52). They often seem unmotivated to participate in experiments that are not interesting to them. More recent work has provided strong evidence to corroborate the earlier anecdotes and the presence of sentience (see e.g. Godfrey-Smith 2016, Catalani 2008, Vitti 2013, Ikeda 2009, Godfrey-Smith 2013, Mather 2008).

Cephalopods have been widely used in scientific research for over a century (Fiorito et al. 2015). Although the UK has had animal protection legislation in place since 1876, this was not extended to cephalopods until the inclusion of Octopus vulgaris in 1993 and all cephalopods in the recent revision of European standards that took effect in 2013 (Andrews 2011). Canada included cephalopods in their 1991 regulations, New Zealand in 1999, some Australian states in 2004, Switzerland in 2008, and Norway in 2009 (Smith et al. 2013). The change to the European standards followed the examination of the evidence (Fiorito et al. 2015) from anatomy, physiology and behaviour) "of cephalopods' ability to experience pain, suffering, distress and lasting harm" (Smith et al. 2013). The change following this legislation was immediate and measurable. Between 2005 and 2011 (prior to the legislation), at least 370 papers on cephalopods were published by EU researchers using methods that could cause pain and suffering (Smith et al. 2013); between 2013 and 2015 no such invasive cephalopod studies were conducted (Fiorito et al. 2015). Had the precautionary principle been used earlier, based on the large body of anecdotal and observational evidence, this may have prevented much of what is now known to be pain and suffering for cephalopods.

4. Conclusion. Statistically significant experimental evidence may be the gold standard for validating the sentience of animals studied, but this may be too demanding for the application 
of the precautionary principle. Where we have relevant anecdotal or observational evidence that the animals are likely to be sentient, from reliable people familiar with the species, this should be accepted not only as a guide for future research, but as grounds for applying the precautionary principle and being more careful in our use of these animals until we have greater certainty. This proposal is compatible with a proportionality principle (Steel 2015) in which we scale the type of action taken to correspond to the degree of available evidence. Hence it does not necessarily entail costly action. That way we could minimise potential harm more effectively and avoid what happened with the cephalopods.

\section{References}

Andrews, P.L.R. (2011). Laboratory invertebrates: only spineless, or spineless and painless? ILAR Journal. 52: 121-125

Bates, L.A. \& Byrne, R.W. (2007). Creative or created: Using anecdotes to investigate animal cognition. Methods. 42: 12-21

Bekoff, M. (2000). Animal emotions: Exploring passionate natures. BioScience. 50: 861-870

Birch, J. (2017). Animal sentience and the precautionary principle. Animal Sentience 16(1)

Burghardt, G.M. (1985). Animal awareness: Current perceptions and historical perspective. American Psychologist. 40: 905-919

Catalani, J. (2008). Cephalopod intelligence. American Paleontologist. 16: 35-39

Croney, C.C. \& Millman, S.T. (2007). The ethical and behavioural bases for farm animal welfare legislation. Journal of Animal Science. 85: 556-565

deFur, P.L. \& Kaszuba, M. (2002). Implementing the precautionary principle. The Science of the Total Environment. 288: 155-165

Enkin, M.W. \& Jadad, A.R. (1998). Using anecdotal information in evidence-based health care: Heresy or necessity? Annals of Oncology. 9: 963-966

Fiorito, G., Affuso, A., Basil, J., Cole, A., de Girolamo, P., D’Angelo, L., Dickel, L., Gestal, C., Grasso, F., Kuba, M. \& Mark, F. (2015). Guidelines for the care and welfare of cephalopods in research - A consensus based on an initiative by CephRes, FELASA and the Boyd Group. Laboratory Animals. 49: 1-90.

Godfrey-Smith, P. (2013). Cephalopods and the evolution of the mind. Pacific Conservation Biology. 19: 4-9

Godfrey-Smith, P. (2016). Other Minds: The octopus, the sea, and the deep origins of consciousness. New York: Farrar, Straus \& Giroux

Heyes, C.M. (1993). Anecdotes, training, trapping and triangulating: do animals attribute mental states? Animal Behaviour. 46: 177-188

Ikeda, Y. (2009). A perspective on the study of cognition and sociality of cephalopod mollusks, a group of intelligent marine invertebrates. Japanese Psychological Research. 51: 146-153

Kamil, A. (1987). A synthetic approach to the study of animal intelligence. Papers in Behaviour and Biological Sciences. 14: 257-308

Linden, E. (2002). The Octopus and the Orangutan. New York: Dutton

Mather, J.A. (2008). Cephalopod consciousness: behavioural evidence. Consciousness and Cognition. 17: 37-48 
Moore, A. \& Stilgoe, J. (2009). Experts and anecdotes: the role of 'anecdotal evidence' in public scientific controversies. Science, Technology and Human Values. 34: 654-677

Moynihan, M.H. (1997). Self-awareness, with specific references to coleoid cephalopods. In R.W. Mitchell, N.S. Thompson \& H.L. Miles (eds.). Anthropomorphism, Anecdotes, and Animals. Albany: State University of New York Press, pp. 213-219

Rollin, B.E. (1997). Anecdote, anthropomorphism, and animal behaviour. In R.W. Mitchell, N.S. Thompson \& H.L. Miles (eds.). Anthropomorphism, Anecdotes, and Animals. Albany: State University of New York Press, pp. 125-133

Russon, A.E. \& Galdikas, B.M. (1993). Imitation in free-ranging rehabilitant orangutans (Pongo pygmaeus). Journal of Comparative Psychology. 107: 147-147

Smith, J.A., Andrews, P.L., Hawkins, P., Louhimies, S., Ponte, G. \& Dickel, L. (2013). Cephalopod research and EU Directive 2010/63/EU: Requirements, impacts and ethical review. Journal of Experimental Marine Biology and Ecology. 44: 31-45.

Steel, D. (2015). Philosophy and the Precautionary Principle. Cambridge: Cambridge University Press

Vitti, J.J. (2013). Cephalopod cognition in an evolutionary context: Implications for ethology. Biosemiotics. 6: 393-401 


\section{ANIMAL CONSCIOUSNESS}

On November 17-18, 2017, the NYU Center for Mind, Brain and Consciousness, the NYU Center for Bioethics, and NYU Animal Studies will host a conference on Animal Consciousness.

This conference will bring together philosophers and scientists to discuss questions such as: Are invertebrates conscious? Do fish feel pain? Are nonhuman mammals self-conscious? How did consciousness evolve? How does research on animal consciousness affect the ethical treatment of animals? What is the impact of issues about animal consciousness on theories of consciousness and vice versa? What are the best methods for assessing consciousness in nonhuman animals?

\section{Speakers and panelists include:}

Colin Allen (University of Pittsburgh, Department of History \& Philosophy of Science), Andrew Barron (Macquarie, Cognitive Neuroethology), Victoria Braithwaite (Penn State, Biology), Peter Carruthers (Maryland, Philosophy), Marian Dawkins (Oxford, Zoology), Dan Dennett (Tufts, Philosophy), David Edelman (San Diego, Neuroscience),

Todd Feinberg (Mt. Sinai, Neurology), Peter Godfey-Smith (Sydney, Philosophy), Lori Gruen (Wesleyan, Philosophy), Brian Hare (Duke, Evolutionary Anthropology), Stevan Harnad (Montreal, Cognitive Science), Eva Jablonka (Tel Aviv, Cohn Institute), Björn Merker (Neuroscience), Diana Reiss (Hunter,

Psychology), Peter Singer (Princeton, Philosophy), Michael Tye (Texas, Philosophy)

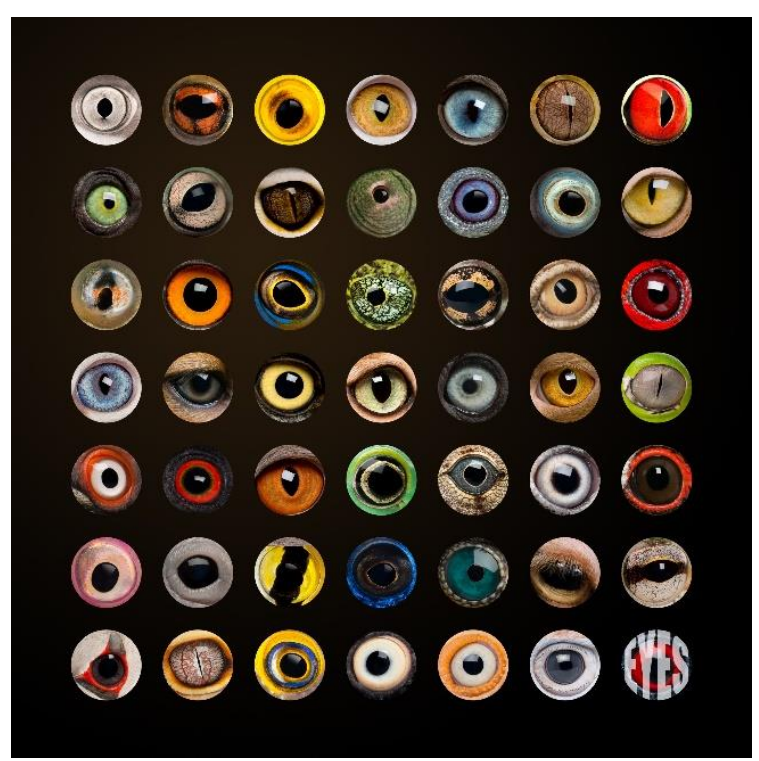

Organizers: Ned Block, David Chalmers, Dale Jamieson, S. Matthew Liao.

The conference will run from 9am on Friday November 17 to $6 \mathrm{pm}$ on Saturday November 18 at the NYU Cantor Film Center (36 E 8th St).

Friday sessions will include "Invertebrates and the evolution of consciousness", "Do fish feel pain?", and "Animal consciousness and ethics".

Saturday sessions will include "Animal self-consciousness", "Animal consciousness and theories of consciousness", and a panel discussion.

A detailed schedule will be circulated closer to the conference date.

Registration is free but required.

\section{Register here.}

\section{See also the conference website}

